\title{
Article
}

\section{Understanding the ecology of host plant-insect herbivore interactions in the fossil record through bipartite networks}

\author{
Anshuman Swain (1D, S. Augusta Maccracken, William F. Fagan, and \\ Conrad C. Labandeira*
}

\begin{abstract}
Plant-insect associations have been a significant component of terrestrial ecology for more than 400 Myr. Exploring these interactions in the fossil record through novel perspectives provides a window into understanding evolutionary and ecological forces that shaped these interactions. For the past several decades, researchers have documented, described, and categorized fossil evidence of these interactions. Drawing on powerful tools from network science, we propose here a bipartite network representation of fossilized plants and their herbivore-induced leaf damage to understand late Paleozoic plant-insect interactions at the local community level. We focus on four assemblages from north-central Texas, but the methods used in this work are general and can be applied to any well-preserved fossil flora. Network analysis can address key questions in the evolution of insect herbivory that often would be difficult to summarize using standard herbivory metrics.

Anshuman Swain. Department of Biology, University of Maryland, College Park, Maryland 20742, U.S.A.; and Department of Paleobiology, National Museum of Natural History, Washington, D.C. 20013, U.S.A. E-mail: answain@terpmail.umd.edu

S. Augusta Maccracken. Department of Entomology, University of Maryland, College Park, Maryland, 20742, U.S.A.; and Department of Paleobiology, National Museum of Natural History, Washington, D.C. 20013,

U.S.A. E-mail: gussieumd@gmail.com

William F. Fagan. Department of Biology, University of Maryland, College Park, Maryland 20742, U.S.A. E-mail: bfagan@umd.edu

Conrad C. Labandeira. Department of Paleobiology, National Museum of Natural History, Washington, D.C. 20013, U.S.A.; Department of Entomology, University of Maryland, College Park, Maryland, 20742, U.S.A.; and College of Life Sciences and Academy for Multidisciplinary Studies, Capital Normal University, Beijing, 100048, P.R.C. E-mail labandec@si.edu
\end{abstract}

Accepted: 10 May 2021

*Corresponding author.

\section{Introduction}

Vascular plants and their insect herbivores collectively account for more than $40 \%$ of terrestrial biodiversity today (Price 2002; López-Carretero et al. 2014) and have dominated terrestrial ecosystems for more than $400 \mathrm{Myr}$ (Wilf 2008; Labandeira et al. 2014). The associations between plants and herbivores are a cornerstone of modern and ancient terrestrial ecosystems, and even conservative estimates for the number of extant plant-insect interactions worldwide are in the tens to hundreds of millions (Labandeira and Currano 2013). Importantly, these interactions likely contributed to the unprecedented diversity of both vascular plants and phytophagous insects through elevated levels of specialization and coevolution (Ehrlich and Raven 1964), spurred in part by the large heterogeneity in the richnesses and associated host-plant specificities among interacting plants and insects (Price 2002). Past studies have elucidated the dynamics of extant plant-herbivore systems through the use of bipartite network

(C) Smithsonian Institution: National Museum of Natural History, 2021. To the extent this is a work of the US Government, it is not subject to copyright protection within the United States. Published by Cambridge University Press on behalf of The Paleontological Society. This is an Open Access article, distributed under the terms of the Creative Commons AttributionNonCommercial-ShareAlike licence (http://creativecommons.org/licenses/by-nc-sa/4.0/), which permits non-commercial re-use, distribution, and reproduction in any medium, provided the same Creative Commons licence is included and the original work is properly cited. The written permission of Cambridge University Press must be obtained for commercial re-use. 
representations and associated statistics (Bascompte 2010). A bipartite network is a specific class of complex networks that have nodes divided into two sets, $X$ and $Y$, and whose nodal links occur between the two sets and not within a set (Simmons et al. 2019). Bipartite network approaches have increased understanding of ecological communities in which they have been studied (Bascompte and Jordano 2007; López-Carretero et al. 2014), such as maintenance of biodiversity in ecological communities, co-phylogeny (Russo et al. 2017), specialization, and other biological traits (Blüthgen et al. 2008).

The insect herbivore diversity within a community is not just a result of local adaptation of insects to local plant species. Such diversity also is influenced by the usability of potential host plants and their relatives and by lineages of insects whose diets have been shaped and determined by millions of years of co-associations and amplified by large-scale environmental gradients (Futuyma and Agrawal 2009). Therefore, it is important to understand the evolutionary history of plant-insect systems and interactions, which remains a relatively young field (Futuyma and Agrawal 2009). Many studies have used phylogenetic approaches to uncover coevolutionary dynamics to disentangle these interactions (Futuyma and Agrawal 2009), but the fossil record provides an outstanding complementary platform for understanding ancient plant-insect associations at macroevolutionary timescales. In many cases, the fossil record is more informative than phylogenetic analyses, as the record of insect herbivory on fossil plants provides probably the most accessible, abundant, and robust evidence of organisms interacting in the distant past.

Here, we use bipartite network-based representations and methods (Bascompte and Jordano 2007) to explore patterns in the structure of plant-insect associations of four floras from the Late Pennsylvanian to middle Permian of north-central Texas, USA. There are inherent problems regarding the use of fossil data for constructing networks, such as preservation, collection bias, number of specimens for each taxon, non-spatiotemporal overlap, and time averaging (Kidwell and Bosence 1991; Dunne et al. 2008, 2014; Roopnarine 2010; Muscente et al. 2018; Shaw et al. 2021). Many of these issues, particularly sampling strategies and standardization of plant-insect interactions, have been explicitly addressed for the fossil record (Schachat et al. 2018, 2020). Through our dataset, these problems are addressed by (1) having a large collection of specimens to prevent statistical errors due to small sample size; (2) collecting a fossil flora from a locality that has narrow temporal variance; and (3) constructing networks with and without rare host-plant species in order to explore the importance of community structure (also see Schachat et al. 2018, 2020). Ultimately, we hope to facilitate use of bipartite network representations to explore and understand fossil plant-herbivore interactions in a new, quantitative way. In the process, we also compare the structure of such interactions across four assemblages spanning different habitats and time intervals.

\section{Data and Methods}

\section{Network Construction from Data}

We constructed weighted bipartite networks using plant-insect associations of four floras from the latest Pennsylvanian to middle Permian of north-central Texas, USA (Schachat et al. 2014, 2015; Xu et al. 2018; Maccracken and Labandeira 2020), wherein network nodes were either plant taxa (at the most highly or lessresolved ranks) or herbivory damage types (DTs) (Labandeira et al. 2007). In such a network, edges represent interactions between the two nodes they connect and are present only between nodes of the two different classes and not between those of the same class. Therefore, an edge can only be present between a DT and a plant taxon in our networks, and each edge denotes the presence of a particular DT in the plant taxon to which it is connected. The width (or weight) of an edge represents the number of occurrences of a given DT in a plant taxon. The width of each node denotes its respective number of occurrences. Each network is normalized according to its total number of DT occurrences and leaf specimens for each node class.

\section{Locality Descriptions}

The four floras used in these analyses were deposited during the Late Pennsylvanian to 
middle Permian of north-central Texas, USA. This interval of time saw considerable environmental change, with the equatorial portions of Euramerica experiencing long-term drying and habitat shifts (DiMichele et al. 1992, 2004, 2005; Gastaldo et al. 1996). In particular, during the Late Pennsylvanian, wetland habitats became restricted to an equatorial belt in Euramerica (Tabor and Poulsen 2008; $\mathrm{Xu}$ et al. 2018), a pattern that was further reduced by the end of the Permian, though the wetlands biome survived in Cathaysia to the end of the period (Tian et al. 1996). The habitats of the four floras reflect these long-term environmental changes.

The youngest of the floras, the South Ash Pasture (SAP) Flora, was deposited during the early part of the Guadalupian Epoch (middle Permian, Roadian), an interval of high aridity in Euramerica (Maccracken and Labandeira 2020). The SAP locality is in King County, north-central Texas, and consists of six sites whose collections are reposited at the National Museum of Natural History (USNM) as three sites (USNM 40968, USNM 41017, and USNM 41662-41665) collected from different excavations within the same sluggish to abandoned channel deposit, thus corresponding to replicate excavations. Each site was excavated within the same 1 -m-thick stratum of the channel deposit, and although it is not possible to estimate the timeline of deposition, time averaging should not be an issue at SAP or any of the other three fossil assemblages. SAP represents a seasonally xeric habitat, and the depositional environment is interpreted as a seasonally dry channel, possibly a tidal channel or small coastal inlet (DiMichele et al. 2004). There are two dominant taxa at SAP: the broadleaved conifer Johniphyllum multinerve (Looy and Duijnstee 2020) and the broadleaved gigantopterid Euparyphoselis gibsonii (DiMichele at al. 2011). Johniphyllum and Euparyphoselis represent the broadleaved condition that bears relatively flat and wide leaves, as opposed to co-occurring taxa such as Pseudovoltzia sapflorensis that bear needle-like leaves. Herbivory at SAP was modest, with 22 DTs and an herbivory index (the percentage of surface area removed by insect herbivores) of 0.88\% (Maccracken and Labandeira 2020).
An older floral assemblage is the late Cisuralian Epoch (early Permian, Kungurian) Colwell Creek Pond (CCP) Flora, which was deposited in an abandoned oxbow channel in a coastal environment with marine influence (Schachat et al. 2014). Similar to the Roadian Age, the Kungurian Age is characterized by increasingly dry climates (DiMichele et al. 2005; Schachat et al. 2014). The CCP locality is in Knox County, north-central Texas, and includes six sites (USNM 41005, 41006, 41007, 42292, 42305, and 42306), which are all replicate excavations from different places within the same claystone stratum that is the lower part of an oxbow lake deposit. CCP has three, codominant, broadleaved taxa-the peltasperm Auritifolia waggoneri, the putative cycadophyte Taeniopteris sp., and the gigantopterid Evolsonia texana (Schachat et al. 2014) - included in this study. Insect herbivory at CCP entailed 52 DTs and an herbivory index of 2.34\%, which is the highest for the four floras in this study (Schachat et al. 2014).

A still older floral assemblage is the midCisuralian Epoch (early Permian, Artinskian) Mitchell Creek Flats (MCF) Flora (Holterhoff 2010), which was deposited in an abandoned channel fill and interpreted as a seasonally dry environment. The MCF locality is in Baylor County, north-central Texas, and consists of three localities that represent three separate collecting events (USNM localities 40049, 40999, and 41661) at the same location. All fossil plant material at MCF was collected from a 55-cm-thick clay layer, most likely deposited in a relatively short period of time. The MCF Flora includes the putative cycadophyte Taeniopteris sp. possibly consisting of multiple similar species, indeterminate broad-leaved pteridosperms, and the gigantopterids Zeilleropteris, Cathaysiopteris, and cf. Cathaysiopteris (Schachat et al. 2015). Three broadleaved taxa are included in this study, consisting of two pteridosperm foliage types and one indeterminate broadleaf. Herbivory at MCF was moderate, with 22 DTs and an herbivory index of $1.98 \%$ (Schachat et al. 2015), comparable to that of CCP and more than double that of SAP and Williamson Drive.

The oldest flora, is the Late Pennsylvanian Epoch (late Gzhelian) Williamson Drive (WD) Flora, deposited in the perennially wet portion 
of a wetlands ecosystem ( $\mathrm{Xu}$ et al. 2018). The late Gzhelian of Euramerica was a relatively warm and wet interval of time. WD was collected at a single locality (USNM 40013) and represents a single roadcut in Jack County, north-central Texas. The WD flora originates from a grayish-brown organic shale that has paper-thin layers forming a lens infilling a channel deposit ( $\mathrm{Xu}$ et al. 2018). There are four major groups of plants at this localitylycophytes, sphenophytes, ferns, and pteridosperms - and a total of 13 broadleaved taxa that are included among these four plant groups. The most abundant plant taxon at this locality is the pteridosperm Macroneuropteris scheuchzeri (Xu et al. 2018), followed by foliage of the sphenopsid Calamites sp. and then the lycophyte Sigillariophyllum sp. Herbivory at WD was diverse, with a total of 46 DTs and a modest herbivory index of $0.86 \%$, nearly identical with the $0.88 \%$ of SAP (Maccracken and Labandeira 2020).

Specimen Collection, Time Averaging, and Taphonomy

The datasets included in this analysis were analyzed by students of the Labandeira Lab at the National Museum of Natural History, between 2011 and 2020. Although time averaging for the four floral assemblages represented in this study needs to be considered, we are confident that plant materials were collected from strata that did not represent long periods of time and during which environmental conditions did not change within each floral deposit. All four localities were collected by William DiMichele, of the National Museum of Natural History, and crew, and the collection protocols remained the same for each fossil assemblage: all recognizable fossil plant material was collected regardless of completeness or size of the specimen. For the studies of plantinsect associations at the four localities, all broadleaved specimens above $0.5 \mathrm{~cm}^{2}$ (or those that are complete and under $0.5 \mathrm{~cm}^{2}$ ) in the MCF, CCP, and SAP floral assemblages were analyzed. At WD, all specimens above $0.25 \mathrm{~cm}^{2}$ were analyzed. Although the lower threshold at WD differs from the other three localities, this difference is not problematic, as only a small proportion of specimens at WD fall between $0.25 \mathrm{~cm}^{2}$ and $0.5 \mathrm{~cm}^{2}$.

All broadleaved specimens from each locality were included in this analysis. Rare host-plant taxa of five or fewer specimens were not included in the analysis, as they represent a minuscule portion of each flora but would dominate the network outputs to a misleading degree. Fossil taxonomic identification was facilitated by William DiMichele, who was involved in the collecting of each fossil assemblage, and also was informed by the relevant Paleozoic paleobotanical literature. All specimens of unknown affinity were removed from the analyses, unless they were clearly attributable to a recognized, yet taxonomically unknown, morphotype. The taxonomic identification of fossil material at SAP was based on a previous paleobotanical analysis (DiMichele et al. 2004), further modified by Looy and Duijnstee (2020). Furthermore, some species and subspecies from WD were lumped together retrospectively after a reanalysis, as they likely represented various morphologies of the same species.

As is the case with the overwhelming majority of paleobotanical studies, the taphonomy of a fossil flora may skew the results and should be briefly discussed. Five taphonomic patterns (MacGinitie 1941; Chaney 1959; Hickey 1977; Burnham 1989) address biases in the paleobotanical fossil record. These patterns are (1) species directly adjacent to streamsides are overrepresented; (2) the differential transport of fossil plants often fragments foliar material beyond recognition; (3) the most abundant taxa were those that grew closest to the site of deposition; (4) the most abundant taxa were also dominant at a particular site or abundant at nearby sites; and (5) floristic differences among collections are attributable to changes in climate or time of deposition that indicate evolutionary trajectories of the floras. Various depositional environments also are known to amass different proportions of the local flora (Burnham 1989, 1993, 2008; Burnham et al. 1992), and the four studies included in this analysis represent different environments, climates, and time periods. Furthermore, the toughness, shape, and size of the leaf are known to create varying probabilities of 
preservation. These factors also affect the extent to which a leaf is attacked by insect herbivores, which could structurally compromise the leaf and cause fragmentation in fluvial environments. Although taphonomic biases almost certainly play a role in the floral diversities and richness at SAP, CCP, MCF, and WD, we assume that the taphonomic biases within these standing-water deposits are consistent enough among these floral assemblages to allow direct comparison of their trophic patterns.

\section{Evaluation of Sampling Effort}

To visualize differences in relative sampling efforts among the four floras, a sample-based rarefaction was calculated (Fig. 1). The rarefaction curve was calculated for DT richness and number of specimens using code developed by S. Schachat (Schachat et al. 2018, 2020) from R statistical software. The data were bootstrapped 5000 times with $95 \%$ confidence intervals, a standard in deep-time plant-insect analyses (Schachat et al. 2018, 2020).

To explore the effect of sampling efforts on the final structure of the fine-scale speciesand genus-level networks, we performed a rarefaction analysis in which we subsampled different proportions of the data (from 0.01 to 1 , in increments of 0.01 ; each repeated 200 times) from each of the four assemblages and measured the Hamming distance (Deza and Deza 2009) between the reconstructed subsampled network and the originally reconstructed network with all the data and normalized for each location for effective comparison. In this context, (normalized) Hamming distance, which takes values from 0 to 1 , summarizes the proportion of interactions recovered from the subsampled data in comparison to the whole dataset and can inform about the relative sampling efforts and how strongly the network structure depends on sampling effort (Swain et al. 2021). This exercise was performed for networks constructed at the species and genus level and at the major plant group level for each of the four localities.

\section{Network Analysis and Metrics}

After constructing the weighted bipartite networks, we used the packages bipartite (Dormann et al. 2008, 2009), vegan (Oksanen et al.
2013), and igraph (Csardi and Nepusz 2006) to calculate and display various network statistics associated with the network structure at each locality. In this analysis, we propose that network measures developed for bipartite networks (Table 1) can be used to understand past plant-herbivore interactions. As detailed in the following sections, we categorize the measures into five groups, depending upon what they measure: centrality, co-occurrence, nestedness, robustness, and specialization, as well as the level of study. The level of study indicates whether the property being quantified pertains to a single node, a class of nodes (such as all DTs or all plants in our case), or the entire network.

Centrality Metrics. - Centrality measures the relative importance of a given node in a network. Here, we use a form of centrality called "closeness" (Dormann et al. 2008), which measures the average farness (or inverse distance) of a node of interest to all other nodes. Distance in the context of networks can be understood as the minimum number of edges that need to be traversed to reach one node from another; therefore, nodes with a high closeness score have the shortest distances to all other nodes. Another simple proxy of centrality is the degree of the node, which is just the sum of edge weights.

Co-occurrence Metrics. - Co-occurrence patterns help explain the distribution of taxa interactions in relation to those of others. The metrics that measure this property include the C-score, which measures the checkerboard (mutual presence/absence) nature of the interactions (Stone and Roberts 1992) at a network level; niche overlap, which measures the mutual similarity of nodes within a given class (Mouillot et al. 2008); togetherness, which measures the average number of shared interactions for a given class of nodes (Stone and Roberts 1992); and functional complementarity, which assesses complementarity in interactions through the aforementioned niche overlaps within a class of nodes (Devoto et al. 2012).

Nestedness Metrics.-Nestedness is an important ecological property that summarizes the degree of substructure within an assemblage. A system is nested when elements of that system that have few constituent parts, such as plant taxa with few interactions, form 

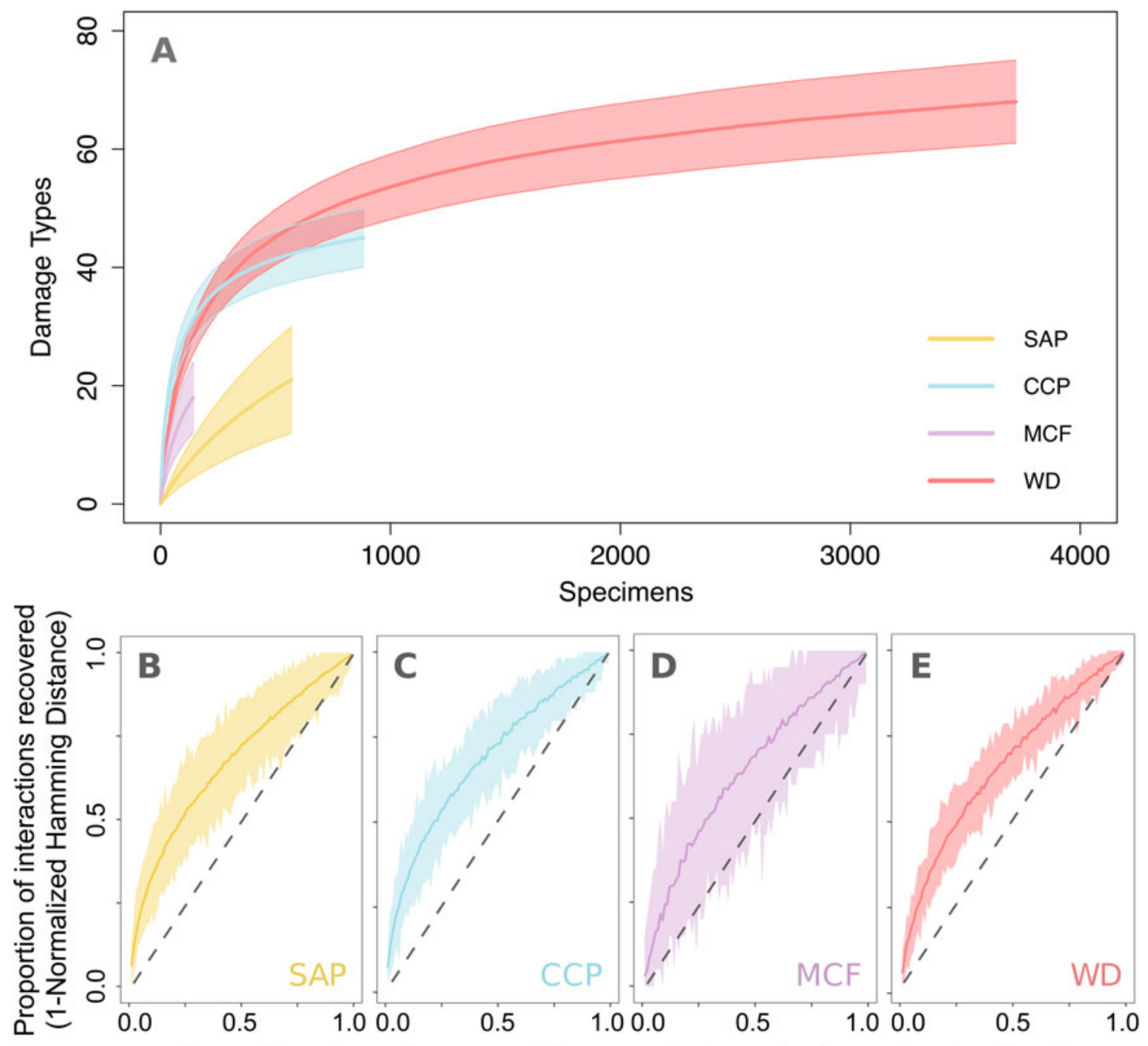

Proportion of specimens used to reconstruct species/genus level networks

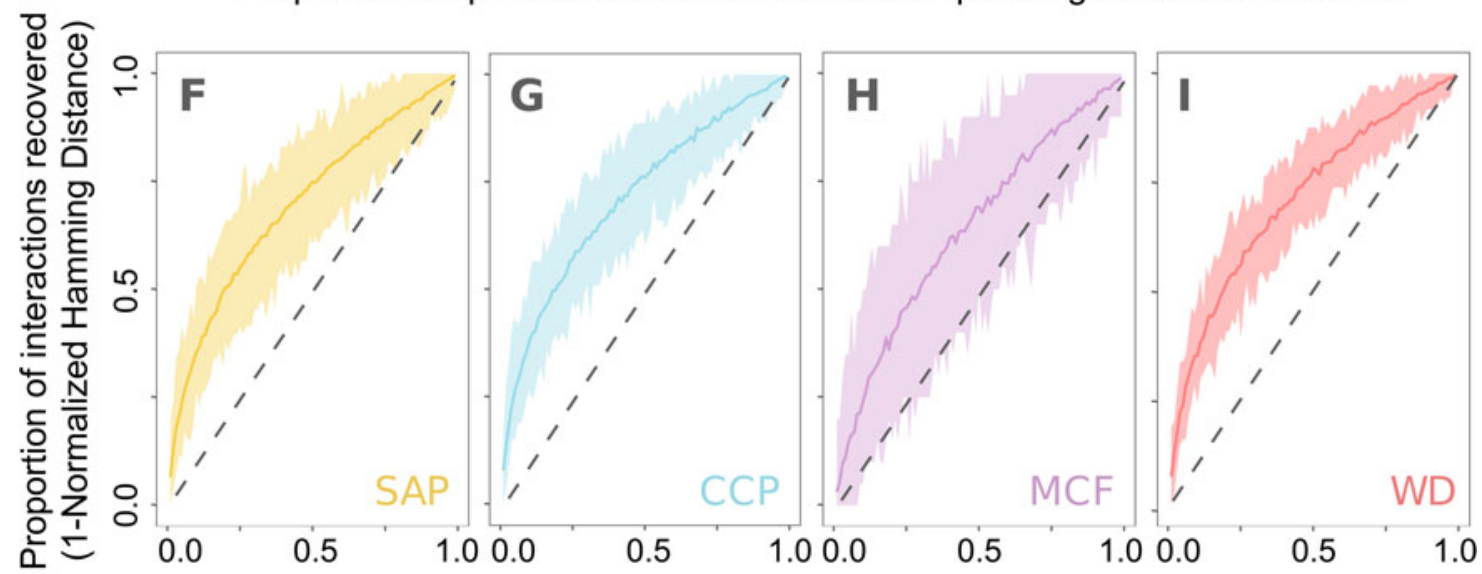

Proportion of specimens used to reconstruct clade/major plant group level networks 
FIGURE 1. A, Sample-based rarefaction of each flora by damage type (DT) richness, including $95 \%$ confidence intervals. B-I, Rarefaction curves for network structure reconstruction at both species and genus levels (B-E) and clade or major plant group levels (F-I), based on normalized Hamming distance, which reveals the proportion of interactions recovered from the networks based on subsampled data. Strong dependence of the network structure on sampling effort is based on the apparent independent and dependent variables in B-I if the mean network rarefaction plot is very close to a line with slope 1. A gray-dotted line with slope 1 has been provided in B-I for reference. The four Paleozoic floras from Texas, USA, used in this study, from youngest to oldest are South Ash Pasture (SAP), of Roadian Age; Colwell Creek Pond (CCP), of Kungurian Age; Mitchell Creek Flats (MCF), of Artinskian Age; and Williamson Drive (WD), of Gzhelian Age.

a subset of the larger system. Several metrics can quantify nestedness in networks, but we used the weighted NODF measure (nestedness metric based on overlap and decreasing fill) to calculate nestedness, as it is considered more consistent and robust than other measures (Almeida-Neto et al. 2008; Almeida-Neto and Ulrich 2011).

Robustness Metrics.-The robustness of natural systems is of great interest because of the potential linkages between robustness and system stability or fragility (Burgos et al. 2007; Memmott et al. 2004). In the context of bipartite networks, taxon-loss slopes-sometimes termed "extinction slopes" (Memmott et al. 2004) - are a measure of system stability and robustness. A taxon-loss slope is calculated by sequential removal of nodes from a given node class (primary node class) and estimation of the number of nodes of the other class (secondary node class) that "survive" by using certain fixed rules for node "survival." The

TABLE 1. Brief description of the network metrics used in this study. DT, damage type; NODF, nestedness metric based on overlap and decreasing fill.

\begin{tabular}{|c|c|c|c|}
\hline Metric & Type & Level & Definition \\
\hline Closeness & Centrality & Node & $\begin{array}{l}\text { Measure of centrality in a network, calculated as the reciprocal } \\
\text { of the sum of the length of the shortest paths between the } \\
\text { node and all other nodes in the graph }\end{array}$ \\
\hline Degree & Centrality & Node & Sum of edge weights per node \\
\hline C-score & Co-occurrence & Network & $\begin{array}{l}\text { Mean (normalized) number of checkerboard combinations } \\
\text { across all nodes }\end{array}$ \\
\hline Functional complementarity & Co-occurrence & Node class & $\begin{array}{l}\text { Measure of ecological niche complementarity, measured as the } \\
\text { total branch length of a functional dendrogram for a given } \\
\text { node class }\end{array}$ \\
\hline Niche overlap & Co-occurrence & Node class & $\begin{array}{l}\text { Mean similarity in interaction pattern between species of the } \\
\text { same node class, calculated using Horn\&rsquo;s index }\end{array}$ \\
\hline Togetherness & Co-occurrence & Node class & $\begin{array}{l}\text { Mean number of co-occupancies across all taxa/DT } \\
\text { combinations for a given node class }\end{array}$ \\
\hline NODF & Nestedness & Network & Measures nestedness based on the overlap of interactions \\
\hline Extinction slope & Robustness & Node class & $\begin{array}{l}\text { Slope of the secondary extinction sequence in a given node } \\
\text { class of a bipartite network, following removal of nodes in } \\
\text { the other node class }\end{array}$ \\
\hline$d$ (Blüthgen's $d$ ) & Specialization & Node & $\begin{array}{l}\text { Measures the degree of interaction specialization at the taxa/ } \\
\text { DT level }\end{array}$ \\
\hline Effective partners & Specialization & Node & $\begin{array}{l}\text { Effective number of partners, if each partner were to be equally } \\
\text { common }\end{array}$ \\
\hline Generality & Specialization & Node class & $\begin{array}{l}\text { Weighted mean effective number of lower trophic level species } \\
\text { (i.e., plants) per higher trophic level ones (i.e., DTs) }\end{array}$ \\
\hline$H_{2}^{\prime}$ & Specialization & Network & $\begin{array}{l}\text { Measure of discrimination, calculated in comparison to no } \\
\text { specialization in a network }\end{array}$ \\
\hline Partner diversity & Specialization & Node class & $\begin{array}{l}\text { Weighted mean Shannon diversity of the number of } \\
\text { interactions for the nodes (taxa/DTs) of a given node class }\end{array}$ \\
\hline Proportional generality & Specialization & Node & $\begin{array}{l}\text { Calculated as "effective partners" divided by effective number } \\
\text { of resources; the quantitative version of proportional } \\
\text { resource use or normalized degree }\end{array}$ \\
\hline Proportional similarity & Specialization & Node & $\begin{array}{l}\text { Specialization measured as dissimilarity between resource use } \\
\text { and availability, calculated through abundance values }\end{array}$ \\
\hline Vulnerability & Specialization & Node class & $\begin{array}{l}\text { Weighted mean effective number of higher trophic species (i.e., } \\
\text { DTs) per lower trophic ones (i.e., plants) }\end{array}$ \\
\hline
\end{tabular}


simplest rule for survival is that a node "dies off" when all its edges are lost. Robustness of the bipartite network can then be estimated from the slope of the curve or the area under it of the fraction of the secondary node class that survived against the fraction of the primary node class removed (Burgos et al. 2007).

Specialization Metrics.-Finally, the specialization of an ecological system is another metric often associated with system stability. One measure of specialization, $\mathrm{H}_{2}{ }^{\prime}$, summarizes specialization at the level of the entire network (Blüthgen et al. 2006) and ranges between 0 (no specialization) and 1 (complete specialization). Other aspects of specialization can be quantified for classes of nodes. For example, generality and vulnerability metrics represent the weighted mean (across nodes within a class) of the number of effective partners that a node in that class (e.g., plants) has with nodes from the other class (e.g., DTs) (Bersier et al. 2002). Finally, the metric partner diversity calculates the weighted average Shannon diversity of the interactions that members of one node class have with members of the other class (Bersier et al. 2002).

At a node level, one can compute a number of different indices that point toward the degree of specialization. Blüthgen's $d$ measures standardized Kullback-Leibler distance in order to estimate the interaction specialization of a particular node (Blüthgen et al. 2006), which leads to a low value of $d$ for generalist taxa (i.e., nodes with a high number of partners) and high $d$ for specialist taxa. The number of effective partners is a measure that takes into consideration whether each partner is equally likely to be found (Dormann et al. 2008). The concept of proportional generality finds the number of effective partners and combines them with the effective availability of nodes of the other classes to calculate a form of normalized degree (Dormann et al. 2008). Finally, proportional similarity quantifies the dissimilarity between available or possible interactions versus actual interactions with the other node class (Dormann et al. 2008). In addition to calculating these network metrics, we implemented a principal component analysis (PCA) on the same data using the R package factoextra (Kassambara and Mundt 2020) to explore possible patterns or clustering of network properties.

\section{Comparison with Modern Plant-Herbivore Interaction Networks}

To compare our reconstructed networks (Supplementary Appendices S1, S2) with their modern counterparts, data were collected for 41 host plant-herbivore interaction networks, representing a variety of habitats and environmental gradients (Michalska-Smith and Allesina 2019; Supplementary Appendices S3-S8). Although the host-plant class of nodes is the same for both the fossil and current networks, the herbivory class is represented by DTs in the former and by insect taxa in the latter. The same metrics were calculated that explored the DT networks of the four Paleozoic floras at the whole-network level and at each node-class level that were also implemented for the modern networks. A PCA was performed for the network metrics obtained at different network levels (whole-network and node-class levels) using the $\mathrm{R}$ package factoextra (Kassambara and Mundt 2020) to document similarities among the localities and within different node classes for the set of modern and fossil networks.

\section{Results}

First, we describe detailed qualitative aspects of herbivory in these four floras that can be extracted from the constructed bipartite networks. Second, we delve into a quantitative comparison among the four floras using network metrics.

\section{Individual Network Structure Descriptions and Ecological Significance}

Network structure varies substantially among the four localities. This likely is attributable to the differences in host-plant taxa and the major differences in functional feeding groups and especially DTs in each of the floras. Our results are listed from the youngest (SAP) to oldest (WD) floras.

South Ash Pasture.-SAP reveals that two host-plant species, a broadleaved conifer Johniphyllum multinerve and the gigantopterid Euparyphoselis gibsonii have nearly separate suites of DTs (Maccracken and Labandeira 

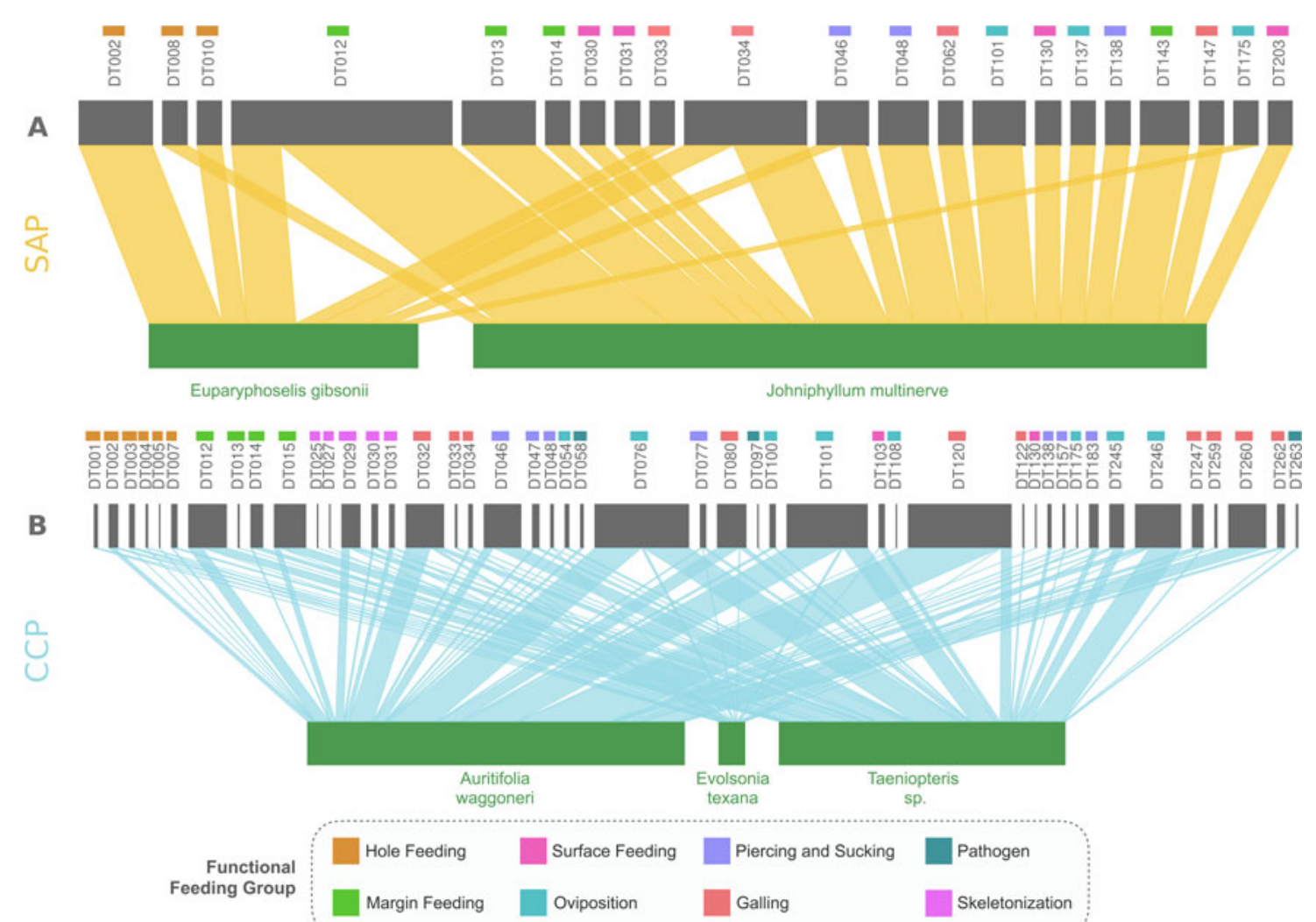

FIGURE 2. Bipartite network representations of plant-damage type (DT) networks at the species and genus levels for four Paleozoic floras from Texas, USA, from younger to older: A, South Ash Pasture (SAP), of Roadian Age; and B, Colwell Creek Pond (CCP), of Kungurian Age.

2020) (Fig. 2A). Insect herbivores are specialized on their particular host plants in this floral assemblage, except for DT12 (margin feeding), DT34 (galling), and DT46 (piercing and sucking), all of which are common in other Paleozoic floras. The species-level and clade-level analyses for SAP are identical (Figs. 2A and 3A). The diversity of insect damage at SAP is also the lowest of the four floras (Fig. 1A).

Colwell Creek Pond.-CCP contains three host plants that collectively had the greatest ranges and overlap of DTs of any plant from the four fossil assemblages analyzed in this study (Figs. 2B and 3B) and is on par with the diversity of insect damage at WD (Fig. 1A). The gigantopterid Evolsonia texana had the lowest incidence of specialized damage, with only two specialized DTs of DT27 and DT175, whereas six, nonoverlapping, specialized DTs each occurred on the peltasperm Auritifolia waggoneri (DT5, DT130, DT108, DT259, DT260, DT258) and Taeniopteris sp. (DT13, DT25, DT97, DT263, DT138, DT122) (Fig. 2B). Auritifolia waggoneri and Taeniopteris sp. had a high number of shared DTs consisting of DT7, DT14, DT46, DT47, DT157, DT183, DT54, DT100, and DT262 compared with those shared between $E$. texana and A. waggoneri (DT4, DT247), and E. texana and Taeniopteris sp. (DT1, DT103, DT33). In particular, A. waggoneri and Taeniopteris sp. shared many endophytic DTs belonging to the oviposition, piercing and sucking, and galling functional feeding groups. Interestingly, the Taeniopteris sp. complex provided the single most diverse suite of DTs, harboring 34 of the 44 total DTs at CCP.

Overall, the plant clades at CCP showed a great deal of overlap among DTs and a relatively small number of DTs associated with a single host-plant clade (Fig. 3B). Although the food web structure at CCP was diverse, the 


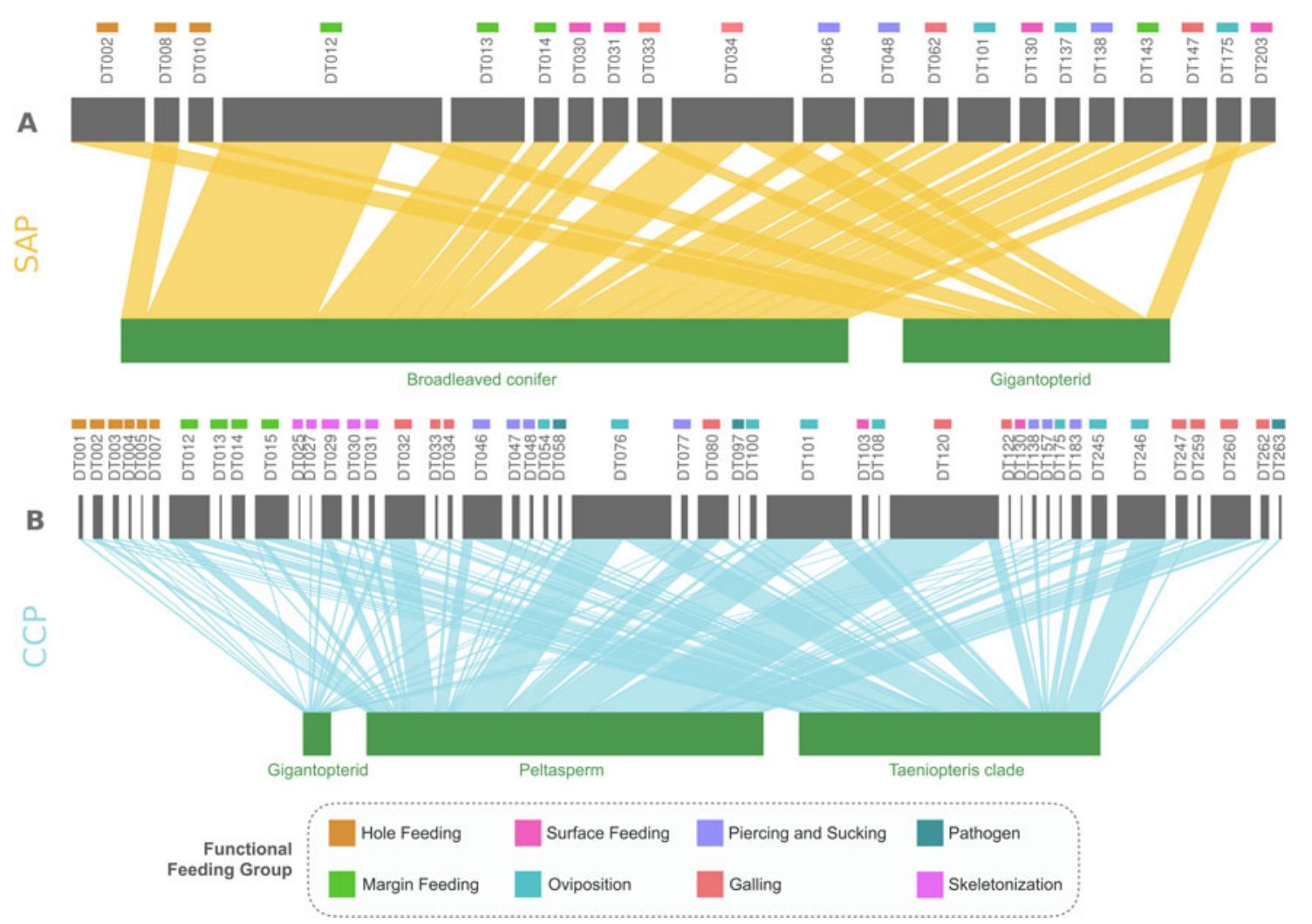

FIGURE 3. Bipartite network representations of plant-damage type (DT) networks at the clade or major plant-group level for four Paleozoic floras from Texas, USA, from younger to older: A, South Ash Pasture (SAP), of Roadian Age; and B, Colwell Creek Pond (CCP), of Kungurian Age.

level of specialization between the plants and insect herbivores was lower than at WD.

Mitchell Creek Flats.-MCF displays herbivory patterns that provide evidence for both specialist and generalist herbivores (Figs. 4A and $5 \mathrm{~A}$ ) but is substantially less diverse than that of WD (Fig. 1A). The form genus Taeniopteris sp., which was the most common element at MCF, had eight specialized DTs, which were not shared among other host plants, consisting of DT13, DT32, DT48, DT67, DT246, DT247, DT265, and DT266 (Fig. 4A) The specialist DTs only found on Taeniopteris sp. were most commonly caused by endophytically (internally) feeding insects, whereas the DTs shared with the other host plants were split more equally between endophytically and ectophytically (externally) feeding DTs. The overlap of Taeniopteris sp. DTs with those of Zeilleropteris sp. was moderate, consisting of DT2, DT12, DT143, DT46, and DT80, whereas overlap with Cathaysiopteris sp. was minimal, with only DT31 and DT101. A greater proportion of endophytic DTs occurred at MCF than at the other localities, although margin-feeding DT12 had relatively more occurrences than all other DTs. Hole-feeding DT2 also was very common. The galling DTs DT80 and DT266 were abundant at MCF.

When analyzed by host-plant clade, a slightly different picture emerges (Fig. 5A). In general, galling DTs were mostly specific to a particular host-plant clade, with the exception of DT80, which is shared with Taeniopteris sp. and gigantopterid host plants. Gigantopterid DTs overlapped fully with Taeniopteris sp., except for surface-feeding DT29 and the gall DT267.

Williamson Drive.-WD is the most complex network of host plants and their insect herbivores. The Late Pennsylvanian WD assemblage (Figs. 4B and 5B) is also the best sampled of the four floras (Fig. 1A). Substantial overlap in DTs 


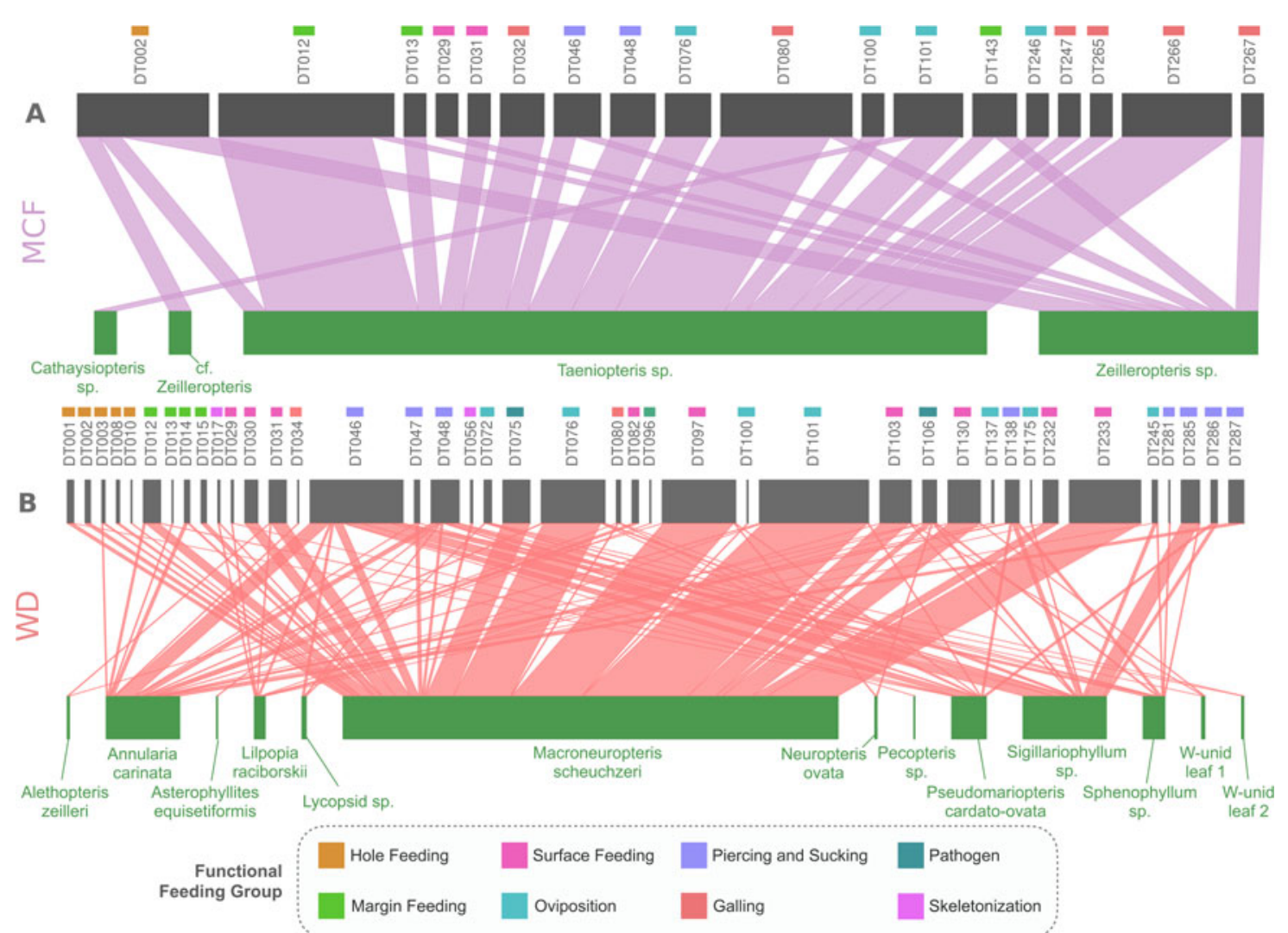

FIGURE 4. Bipartite network representations of plant-damage type (DT) networks at the species and genus levels for fourPaleozoic floras from Texas, USA, from younger to older: A, Mitchell Creek Flats (MCF), of Artinskian Age; and B, Williamson Drive (WD), of Gzhelian Age.

exists among host-plant clades at WD (Fig. 5B). Macroneuropteris scheuchzeri, the most abundant host plant at WD, has 26 DTs, of which nine are exclusive to this host plant. Other host plants share at least one DT with $M$. scheuchzeri, and display substantial overlap with the sphenophyte, Annularia carinata. Interestingly, the lycophyte Sigillariophyllum sp. has an equivalent richness of DTs compared with A. carinata, but relatively fewer overlapping DTs with $M$. scheuchzeri.

When analyzing the proportions of DTs across the whole flora, the piercing and sucking DTs of DT46, DT48, and DT138 have notable overlap in host plants, and DT46 is an abundant DT at WD. Oviposition also is common at WD, although the vast majority of instances are DT101 on $M$. scheuchzeri. Various surface-feeding DTs, such as DT30, DT31, and DT233, are also frequent, yet few host plants exhibited hole feeding.
When the network is analyzed by host-plant clade, the general patterns of host specificity of DTs become more obvious (Fig. 5B). Pteridosperms make up the majority of specimens and have the greatest proportion of DTs. Although all three clades-the pteridosperms, lycopsids, and sphenophytes -overlap greatly in their DTs, lycopsids appear to have more generalized DTs. There is only one instance, oviposition DT175, of a specialized DT, or a DT only occurring within a single clade, on lycopsid tissues. Alternatively, sphenophytes have the 7 specialized DTs of DT13, DT34, DT82, DT96, DT137, DT281, and DT287, and pteridosperms have the 11 specialized DTs of DT1, DT2, DT8, DT10, DT15, DT30, DT56, DT75, DT97, DT100, and DT233. The overall level of specialization between host-plant clade and insect herbivores at WD is greater than at other, less 


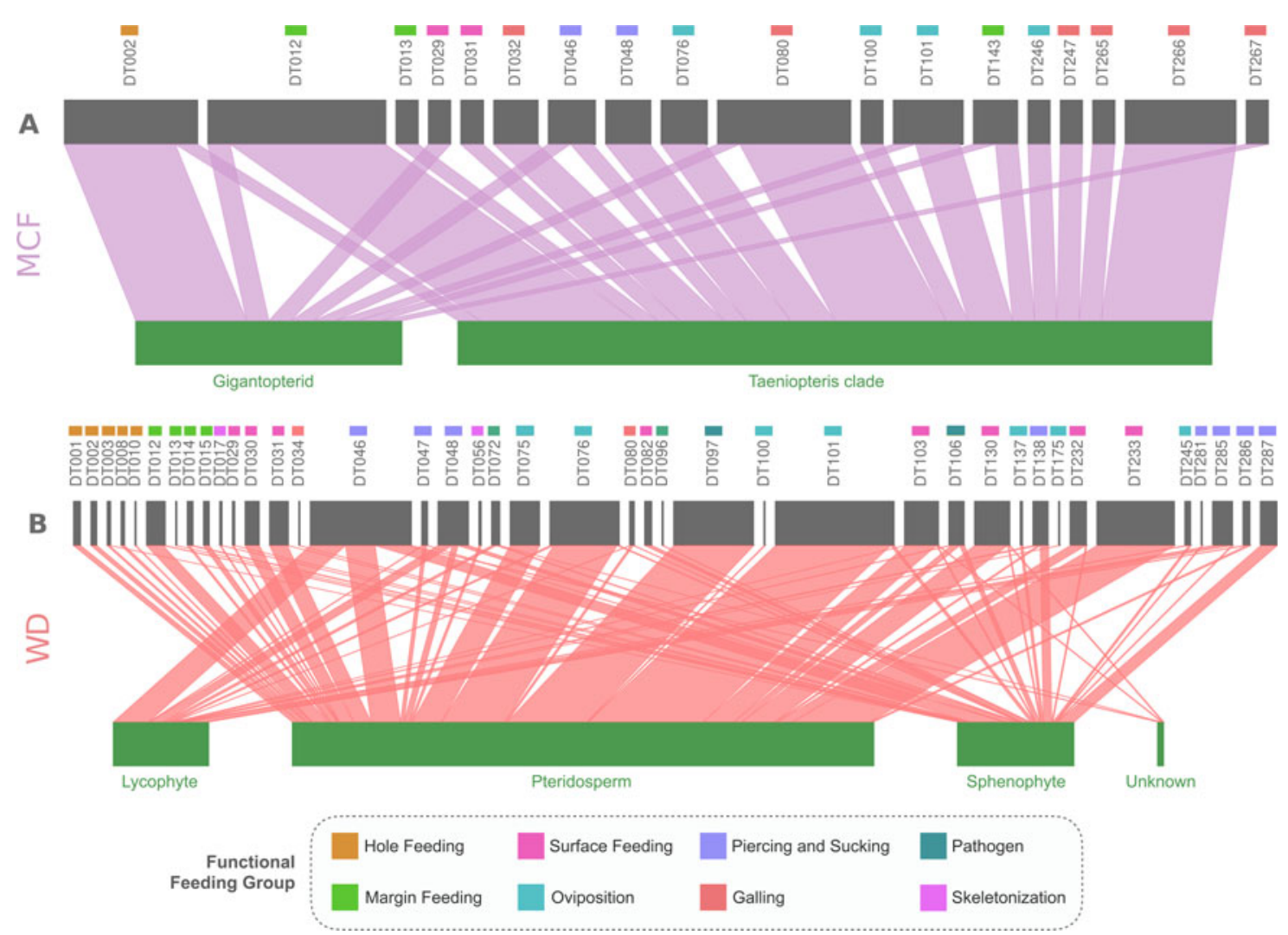

FIGURE 5. Bipartite network representations of plant-damage type (DT) networks at the clade or major plant-group level for four Paleozoic floras from Texas, USA, from younger to older: (A) Mitchell Creek Flats (MCF), of Artinskian Age; and B, Williamson Drive (WD), of Gzhelian Age. The plant morphotype, W-unid, refers to an unidentifiable, woody, vascularplant axis found in the WD flora.

diverse fossil assemblages analyzed in this study, especially CCP.

\section{Rarefaction Analysis}

A sample-based rarefaction analysis for the plant-insect associations of the four Paleozoic floras illustrates the differences in sampling effort among the deposits (Fig. 1A). Confidence intervals for WD and CCP overlap, indicating that they have similar DT richnesses, while both MCF and SAP have lower DT richnesses. Strong dependence of sampling effort on the network structure is observed if mean network rarefaction plots asymptotes to a line with a slope of 1 . Results from the network rarefaction analysis (Fig. 1B-I) in this study indicate no such dependence in any of the eight constructed networks. It is evident that at less than $25 \%$ sampling, more than $50 \%$ of the interactions are recovered, and that $90 \%$ recovery of interactions encompass about $75 \%$ of the data in all cases. In other words, $50 \%$ of the network structure is recoverable from a quarter of the data, and most (>90\%) of the network structure is recoverable from approximately threequarters of the data, thus displaying robustness of the network structure to sampling errors and biases. Among the four floras, MCF seems to have the largest variability with respect to network reconstruction from the available data, due to the small number of specimens from the locality (Fig. 1A,D,H) and might hint at slight undersampling.

\section{Comparative Analyses Using Network Metrics}

At the level of the individual network, qualitative descriptions also can be condensed in some form using network-level or node classlevel metrics (Table 1). The metrics that measure specialization, such as mean number of 
shared partners, generality, vulnerability, and partner diversity, illustrate that the interactions at CCP are less specialized for both the plant and herbivory levels. CCP additionally is characterized by a high degree of nestedness, wherein herbivory interactions of a host plant with a smaller number of DTs is a subset of the host plants with a higher number of interactions. In contrast, SAP has a distinct checkerboard-like pattern of interactions among its plants, as seen through its $C$-score at the host-plant level, in which the majority of DTs are specialized for a particular host plant. The taxon-loss slopes for both plants and DTs also suggest specialization at the node-class levels, with large absolute values indicating an abrupt loss of nodes during the slope calculation process. This loss is indicative of a high initial redundancy in the network, as is the case with CCP, and the reverse for SAP. The two other localities have intermediate values in the measures of specialization, co-occurrence patterns, and robustness.

PCA of node-level network characteristics for the networks revealed two interesting patterns. The first is the clustering of network properties for DTs that are to some extent categorized by locality and not by functional feeding group or DT classification. This categorization occurred even though the first two PCA axes jointly explained $78.5 \%$ of the variance among the DT network indices (Fig. 6A-C). Similarly, the first two PCA axes explained $84.2 \%$ of the variance among the indices at the plant species level (Fig. 6D-F). Here again, locality identity performed better than plant clade affinity when estimating clusters using the first two PCA axis values. The two axes of node properties that differentiated the array of indices among the DTs and plant species exhibited substantial overlap; in both the cases, specialization and co-occurrence indices dominated the first PCA axis and Blüthgen's $d$ metric dominated the second axis (Fig. 6C,F). The centrality and proportional similarity indices played an additional role in the second PCA, and to a greater degree for host plants (Fig. 6C). Blüthgen's $d$ measures the asymmetry in the specialization of a given class (either DTs or host plants) with respect to its interacting partners as well as their rarity (abundance) and therefore provides a different perspective on "specialization" when compared with other specialization and co-occurrence metrics that form PCA axis 1 in both DT and host-plant cases (Fig. 6C,F). This differentiation becomes important when we look at finer patterns at the level of the clade or major plant group for host plants and at DT classification.

Plant clade or major group affinity, although not the best predictor of clusters, did result in some broad, interesting patterns. The Cycadophytes (Fig. 6E), although from two different locations (CCP and MCF), cluster based on their network properties and tend to have a high number of effective partners, along with other related metrics detailed on PCA axis 1 (hereafter termed generalization indices). Cycadophytes also have a consensus low value of Blüthgen's $d$ metric, which informs generalist host-plant behavior with generalist DTs. By contrast, pteridosperms were specialists with low values of generalization indices, with the sole exception of $M$. scheuchzeri, but had a wide range for Blüthgen's $d$ metric (Fig. 6E). Blüthgen's $d$ metric symbolizes that, even though these taxa had few effective partners, the degree to which their partners were specialized or generalized differed, leading to varied $d$ values. Sphenophytes had low values of specialization metrics, making them specialist host plants, and all except $A$. carinata have low values of Blüthgen's $d$ metric, indicating a high specificity of DTs (Fig. 6E). A similar trend is seen in the lycophytes, which have low specialization indices but vary in Blüthgen's $d$ metric (Fig. 6E). Gigantopterids have a trade-off link relationship among Blüthgen's $d$ metric and generalization metrics, notable for taxa having higher values of generalization that tend to have low $d$ values (Fig. 6E). This suggests that either taxa had high number of specialist (and/or rare) interactions or a low number of generalist (and/or common) interactions, at least in this limited dataset of the four localities.

The patterns in DT classifications primarily depend on locality identity (Fig. 6A), but also show certain dependence on whether they are specialized or generalized (Fig. 6B). The example of two DT classes, piercing and sucking and surface feeding, illustrate these trends. Piercing and sucking DTs are spread across the 
For Damage Types (DTs)

A
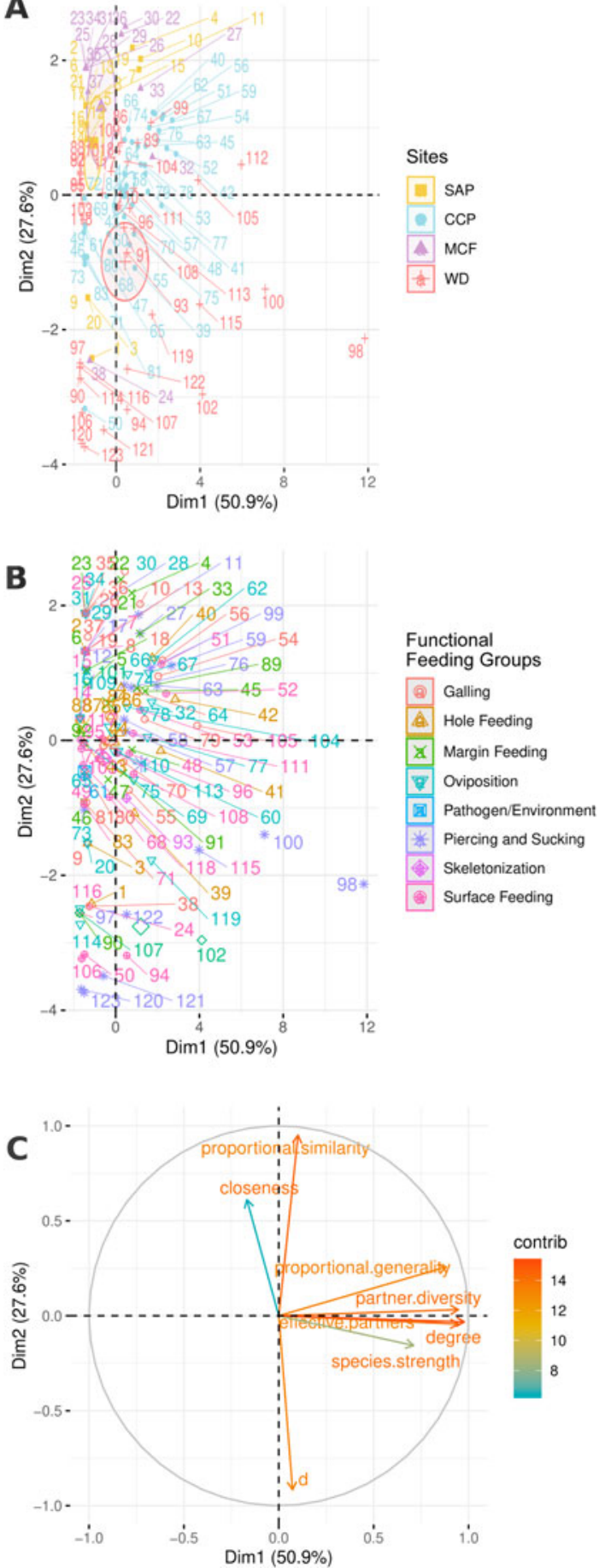

For Host Plants
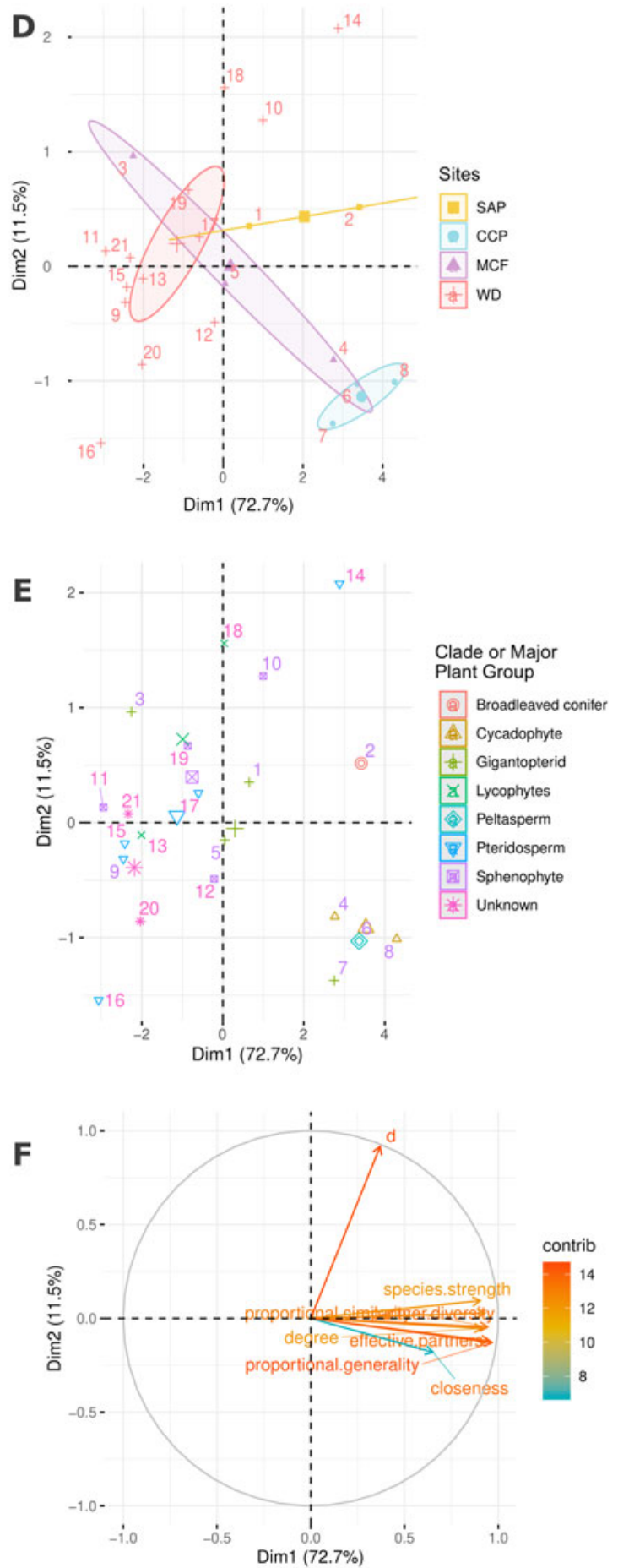

FIGURE 6. Principal components analysis (PCA) of network metrics of damage types (DTs) (A-C) and by host plants in (D-F), colored by localities in A and D, by type/class of DT in B, and by the clade or major plant group of host plants in E. C and F, The contribution of various network metrics in the PCA for DTs (left) and host plants (right) as a percentage of the explanation of the variance. Numbers in subplots A, B, D, and E are used as identifiers instead of DT names or host-plant names for ease of identification across localities, to avoid confusion in the case of shared names, and for brevity. See "Data and Code Availability" for details about the numerical identifiers. The PCA axes PC 1 and PC 2 are equivalent to Dim1 and Dim2, respectively. 
PCA plane-giving way to three major groups among themselves (Fig. 6B). Many DTs such as DT46 (in Fig. 5B), DT48, and DT138 have higher values of generalization indices as well as high values of the $d$ metric, showing a high level of generalized behavior, but on a large proportion of rarer host plants (Fig. 6B). Other piercing and sucking DTs such as DT281 and DT285-DT287, are specialized and affect rarer plant hosts, leading to lower generalization indices and a very high $d$ value (Fig. 6B). The rest of the piercing and sucking DTs are moderately specialized and have lower values of $d$, signifying presence on common plants (Fig. 6B). Surface feeding similarly can be categorized into three groups: extremely specialized DTs with high $d$ values and low generalization indices, such as DT27 (no. 50) and DT83 (no. 106); specialized DTs found on more abundant host plants with low generalization indices and low values of the $d$ metric, such as DT30 (no. 52), DT31 (no. 53), DT97 (no. 108), and DT103 (no. 111); and moderately generalized DTs with low values of $d$ metric and a moderate value of generalization indices, such as DT25 (no. 49) and DT75 (no. 103) (Fig. 6B). But care must be taken in extrapolating these values, which are based on locality-specific factors such as presence, diversity, and abundance of host-plant taxa. To put this in perspective, consider the example of surface-feeding DTs DT29 and DT30. DT29 is present in CCP, MCF, and WD and, in the latter two cases, is an extremely specialized DT with high $d$ value and low generalization indices; by contrast, in CCP, surface feeding is less specialized, with low $d$ value and moderate values of generalization indices. DT30 is found at CCP, SAP, and WD; in the latter two localities, it is specialized but found on a very common host plant, but in CCP, it is less specialized. One valuable feature of this analysis is its use at single localities to obtain deeper insights into the interactions at a specific locality or, alternatively, at a very large cluster of localities to generalize and extrapolate broader results.

\section{Comparison of Fossil with Modern}

Plant-Herbivore Interaction Networks

On comparing modern with fossil plantherbivore networks using PCA, we found that similar clusters of metrics governed the description of variance in node-class characteristics for both modern and fossil networks (Figs. 6, 7). Generalization metrics, such as partner diversity, effective partners, and species strength tend to cluster together and are almost orthogonal to Blüthgen's $d$ metric. This orthogonality is true for both host plants and insect herbivores/DTs (Fig. 7, Supplementary Fig. S1). In case of the latter pattern, the fossil DTs reside within the area occupied by modern insects in PCA space (Fig. 7 E,F and Supplementary Fig. S1). However, fossil DTs and modern insect herbivores do not represent the same ecological meaning. In the case of host plants, except for those belonging to WD, all fossil taxa exhibited higher proportional generality and closeness when compared with those from modern networks (Fig. 7 C,D and Supplementary Fig. S1). This result is expected, given the low richness of host-plant taxa at the three fossil localities compared with that of WD and the relative number of DTs present for each locality with respect to the total DTs present among all localities.

While comparing the overall network structures across the modern and fossil systems, we see that the fossil localities differ slightly regarding niche overlap, nestedness (NODF), connectance (proportion of interactions observed divided by all possible ones), and possibly robustness. Interestingly, none of the fossil localities stand out explicitly and have at least one modern analogue adjacent to their fossil equivalents in PCA space (Fig. 7A,B). These slight differences might be attributable to close comparisons of DTs with insect taxa in the networks. Previous literature has shown that DT richness in certain cases, such as margin feeding, track insect richness in modern ecosystems (Carvalho et al. 2014), but DTs are more limited in number and lack functional representation, such that every DT is not uniquely paired with a member of the other set, resulting in absence of one-to-one pairings between measured herbivore damage and the herbivore(s) creating that damage. For example, some insect taxa can inflict damage through multiple DTs, whereas other, multiple insect taxa can collectively herbivorize plants through the same DT (Carvalho et al. 2014). 

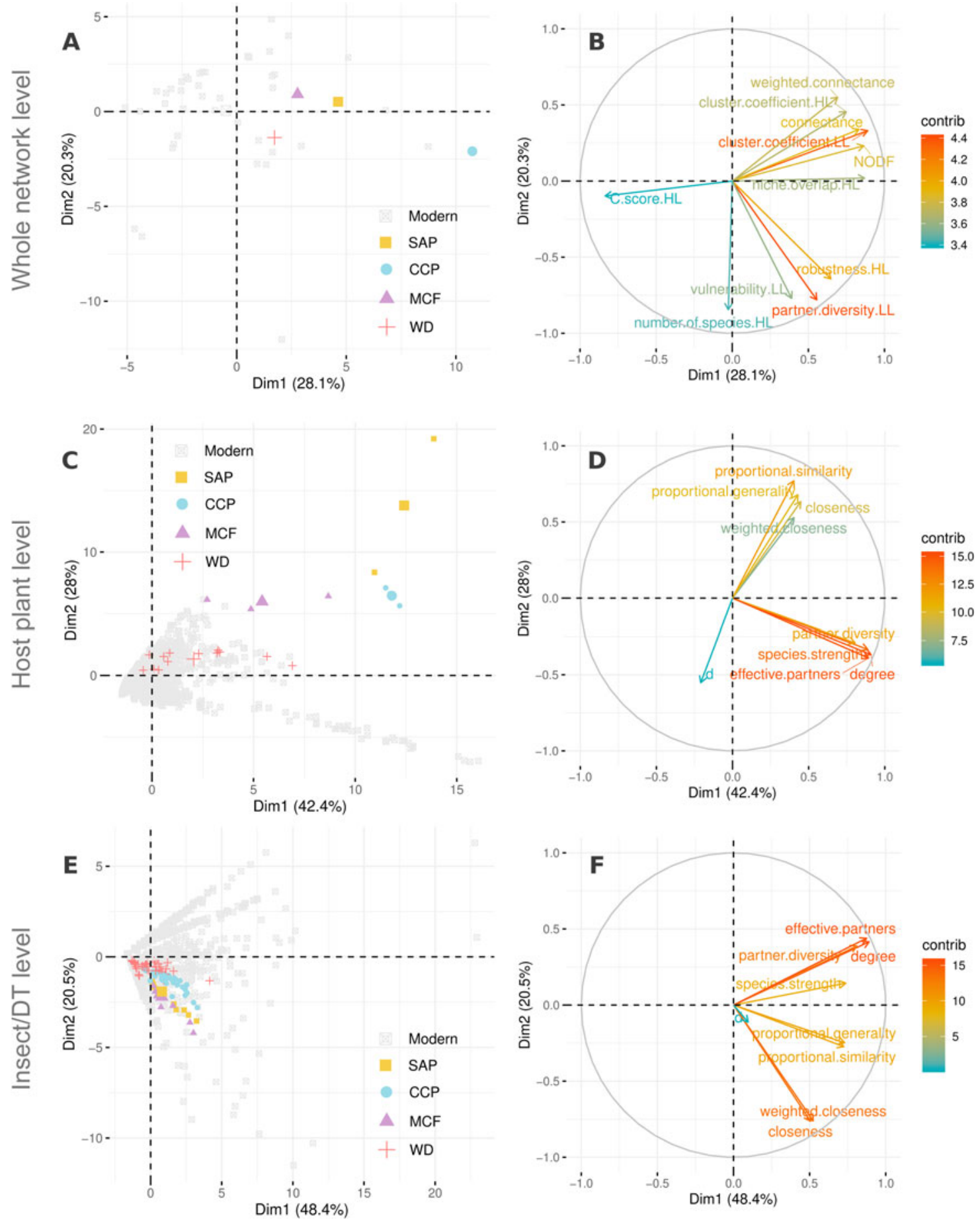

FIGURE 7. Principal components analysis (PCA) for comparison of network metrics among modern and fossil networks, at the whole-network level (A, B), among host plants (C, D), and among insect herbivores or damage types (DTs) (E,F) colored by locality in A, C, E. B, D, F, The contribution ("contrib") of various network metrics as a percentage of the explanation of the variance for the PCA at network level, among host plants, and among insects/DTs, respectively. For a list of the modern host plant-herbivore networks included in this study, see "Data and Methods." The four Paleozoic floras from Texas, USA, used in this study, from youngest to oldest are South Ash Pasture (SAP), of Roadian Age; Colwell Creek Pond (CCP), of Kungurian Age; Mitchell Creek Flats (MCF), of Artinskian Age; and Williamson Drive (WD), of Gzhelian Age. The PCA axes PC 1 and PC 2 are equivalent to Dim1 and Dim2, respectively. 
These characteristics can make DT-based herbivory networks a more trait-based representation of an insect DT network. Consequently, DT-based herbivory networks may introduce redundancies due to the absence of one-to-one mapping of interactions and increase niche overlap, nestedness, and connectance, as well as robustness.

\section{Discussion}

Network analyses of ancient plant-insect associations have the potential to change our understanding of the evolution of deep-time terrestrial ecology. Although networks of host plants and insect herbivores are commonly used in neontological analyses, these networks also are valuable for understanding how plant-insect associations have changed through time, across space, in different habitats, and among various floras of special interest. Here, we analyzed four late Paleozoic floras from Texas that differ in host-plant community structure, DT diversity, geologic age, and environmental setting. Our results reveal differences among the four floras and demonstrate the potential utility of network analysis. We also compared the structures of fossil plant-DT networks to modern plant-herbivore networks to get a perspective on the similarities and differences between the two. However, it must be noted that, unlike the neontological networks, analyses of ancient floras may only use the damage inflicted on fossil plants to build the said networks and might not be directly comparable to their modern counterparts.

\section{Fossil Network Comparisons}

The four late Paleozoic floras-SAP, CCP, $\mathrm{MCF}$, and WD-were very different from one another in terms of the diversity of host plants, suites of DTs, and levels of complexity and specialization. WD, the oldest and most diverse flora, also had the most complex herbivory network. A wide range of specialist and generalist DTs were present, most notably on the most abundant host plant, the pteridosperm Macroneuropteris scheuchzeri. When plants were categorized by clade, lycopsids had more generalized damage than either sphenopsids or pteridosperms, in that there were no lycopsid-only DTs. In comparison to WD, the CCP flora also had a complex network of plant-insect associations, with a high richness of DTs, but relatively less specialized herbivory. DTs overlapped considerably among the three, major host plants at CCP, although specialized DTs occurred on each of the host plants. Despite the vast difference in host-plant richness between WD and $\mathrm{CCP}$, the complexities of these networks are comparable. MCF and SAP both had low host-plant diversities, similar to CCP, but expressed greatly diminished suites of DTs. Insect herbivory at MCF exhibited a mix of generalized and specialized damage for each of the three host plants, whereas the herbivory at SAP was overwhelmingly specialized.

The major observations we point out using PCA of network metrics for both DTs and floras is that network properties cluster by locality rather than by DT category. For both DTs and host-plant clades of each of the four floras, we suggest that each locality fostered its own generalized and specialized suites of herbivore communities on particular host plants. These source plants and their herbivores harbored interactions that probably evolved and were stabilized based on the local environment and ecological structure of the biota.

Although examining comparable, additional floras centered on the lower Permian of northcentral Texas would be necessary to make more concrete assessments, we have established interesting, preliminary patterns for these four floras and their insect herbivores. First, floras from the water-rich habitats surrounding the depositional environments of WD and CCP had more complex networks of plant-insect associations, although they differed in levels of herbivore specialization. The comparatively xeric habitats from which the floras of MCF and SAP were drawn had lower richness of DTs and simpler networks of plant-insect associations. The sampling effort for each flora, possibly also confounded with their differing depositional environments for the more hydric floras, may have contributed to these two contrasting networks of herbivores (Fig. 1). The more complex networks of WD and CCP derived from the greatest 
sampling efforts. (Sample sizes were WD with 2127, CCP with 883, SAP with 570, and MCF with 142 specimens.) Consequently, issues such as sampling effort may have contributed to disparities in network complexity (Schachat et al. 2020).

Intrinsic Patterns in the Evolution of Herbivory

As hinted earlier in this report, the bipartite network analyses for these four late Paleozoic localities provide several avenues for understanding the evolution of insect herbivory in time and space. Discussed here are four aspects of insect herbivory that can be teased apart by reference to the analytical methods used herein. They are (1) herbivory levels in general; (2) the role of herbivore specialization; (3) the structure of component communities; and (4) network metric clustering based on the relative importance of locality, plant, and DT variables.

Although the herbivory index is a single number for a given flora, a more meaningful assessment of such a single number would be to understand the inputs to this number. For example, what are the relative contributions of functional feeding groups to the herbivory index? For the latest Pennsylvanian to earliest middle Permian examples mentioned here, this would include, in the broadest sense, the proportional representation of externally feeding (hole feeding, margin feeding, and surface feeding) versus internally feeding (oviposition, piercing and sucking, and galling) functional feeding groups. In a narrower sense, do the presence of a few DTs represent overwhelmingly the bulk of herbivory? Floras with similar herbivory indices may have very different sources for their herbivory.

The degree of herbivore specialization can reveal how plants are partitioned in a fossil flora. Are certain plant hosts solely herbivorized by a group of host-specialist insects, as revealed by their limited and unique DT spectrum when compared with other plants in the flora? Is the same host also consumed by generalist insects as well, or do generalist insects only consume other plants? Alternatively, when viewed in light of insect damage patterns, are certain tissues, such as mesophyll, phloem, or meristems, preferentially consumed by certain insects, as reflected by their distinctive, associated DTs? The evolution of elevated host specificity in plant-insect interactions may represent a sudden occurrence when a host becomes available or a prolonged process of adaptation.

An important consequence of bipartite networks is that they reveal the component herbivore communities of the major plants in a fossil flora (Figs. 2-5). (A component community consists of a source plant species and all of the species that are directly dependent trophically, including herbivores, but also saprobes, and ideally the predators and parasitoids of those herbivores.) The distribution of links between a source plant and its herbivores provides data on the structure of the of the component community, such as the balance between externally and internally feeding herbivores, the absence of certain feeding guilds, and the presence of physical and chemical plant defenses.

As alluded to earlier (Fig. 6), the multivariate clustering of node-level network properties expressing centrality, co-occurrence, nestedness, robustness, and specialization can be categorized according to locality, plant host, or DT classification. This categorization reveals the broader node-based structure of each locality. More importantly, the categorization provides a comparative method for evaluating different node-based network structures of multiple localities that can extend beyond the level of the component herbivore communities.

Comparison with Modern Plant-Herbivore Networks.-We attempted to understand similarities and differences between the structure of fossil and modern networks through network metrics at the different levels of the host plant, the insect herbivore taxon or DT, or the whole network (Fig. 7, Supplementary Fig. S1). A probable reason for the similarity is the difference between the nature of DTs and of insect taxa. DTs can be thought of as functional, traitbased representation of insect taxa, as measured by herbivory damage. The observation that in some cases the same insect species can inflict multiple DTs on plants, whereas in some other cases multiple insect species can inflict the same DT, makes DT a divided trait when the insect and plant diversity is low, resulting in increased nestedness, robustness, and connectance in plant-DT networks, as 
compared to plant-insect networks. The same trait can be an aggregate trait when the diversity is very high, making DTs very similar to plant-insect networks. A research initiative for future studies would be to compare fossil versus modern plant-DT networks, as well as modern plant-DT networks versus modern plant-insect networks, to uncover underlying patterns of similarity or difference.

Although exact comparisons of modern and fossil plant-herbivore networks are not possible due to differences in data collection, attributed, for example, to the absence of insect taxonomic data preserved in fossil plant-insect associations, we likely are able to recognize similarities in large-scale patterns present in modern networks. Patterns observed in plantherbivore networks of both modern and ancient ecosystems could assist paleobiologists in understanding the abiotic and biotic drivers responsible for these patterns. By contrast, differences between modern and fossil plantherbivore networks may illuminate how terrestrial ecosystems have changed over time. For instance, Oliveira et al. (2020) tested plantherbivore network topology in modern Neotropical savannas for specific feeding guilds, which are akin to the functional feeding groups used by paleobiologists. They found differences in the specialization of interactions between endophytic (internally feeding) and exophytic (externally feeding) guilds that were associated with the defensive properties of plant hosts as well as the sizes of the constituent networks (Oliveira et al. 2020).

López-Carretero et al. (2014) found that stressful environments supported more generalist insect herbivores and the diversification of resource use in a seasonal tropical ecosystem. Such a pattern may be explicitly tested in future paleobiological studies that use more spatiotemporally constrained networks. Additionally, López-Carretero et al. (2014) examined temporal variation in plant-herbivore networks from a seasonal tropical ecosystem and found that temperature and precipitation influenced plant diversity and defensive properties, which in turn influenced the networks of plants and insect herbivores. These results are similar to those found in this study, wherein the wetter floras (WD and CCP) had more complex networks than the more xeric and seasonally influenced localities (SAP and MCF).

\section{Role of the External Environment}

The analyses presented here also represent an initial step toward a general framework for understanding the effect of the external environment in ancient plant-insect associations. The data come from only four floras, although there are numerous studies of scores of fossil localities that could be analyzed in these ways. Additional network analyses of additional floras that integrate abiotic and biotic sources of environmental transformation would certainly refine and improve our understanding of how ancient plant-insect associations changed through time, yielding insights into both evolutionary and ecological questions beyond that of habitat differences among the four Paleozoic floras. Additional refinements of comparisons of insect herbivory on floras across extinction events, such as the PermianTriassic (Labandeira et al. 2016) or Cretaceous-Paleogene (Labandeira et al. 2002; Wilf et al. 2006) boundaries, or periods of rapid climate change, notably the PaleoceneEocene thermal maximum (Wilf and Labandeira 1999; Currano et al. 2010), would be useful. Likewise, network analyses of ancient plant-herbivore networks also could inform understanding of the biotic changes associated with tectonic activity, such as the breakup of Gondwana (Labandeira et al. 2018) or the convergent merging of the Indian Plate with the Eurasian Plate. Although the Paleozoic floras analyzed herein should be precluded from comparisons to extant floras, younger Cenozoic and probably Cretaceous floras could be used to contrast modern versus fossil plant-herbivore networks. Such analyses would mark an important fusion between ecological research in the modern world with deep-time paleobiological research in service of understanding how vascular plants and their arthropods have come to dominate the terrestrial realm.

\section{Acknowledgments}

We thank two anonymous reviewers and C. Looy and K. Boyce, whose suggestions greatly 
improved the article. We thank S. Schachat, Q.-Q. Xu, B. DiMichele, D. Chaney, A. Rulis, J.-H. Jin, J. Gordon, M. Halthore, S. Levi, and J. Alvarez for obtaining data from the four analyzed localities. W. DiMichele provided a presubmission review of the article. We are grateful to the Smithsonian Volunteer Program at the National Museum of Natural History for allowing A.S. to work and forge this collaboration. A.S. also would like to thank the COMBINE program at the University of Maryland (NSF award DGE-1632976) for technical and academic support. W.F.F. and A.S. also thank the University of Maryland for support. This report is contribution 389 of the Evolution of Terrestrial Ecosystems consortium of the Smithsonian's National Museum of Natural History in Washington, D.C.

\section{Data and Code Availability}

All data used in this work are available as Supplementary Material (Supplementary Appendices S1-S8). All of these datasets under the title "Bipartite Network Datasets for Permian Host-Plant-Insect Herbivory" are accessible through the Dryad Digital Repository at https://doi.org/10.5061/dryad. 9ghx3ffh9. The raw fossil data can be found in the file Appendix S1.Fossil_Data.csv. Nodelevel network metrics for DTs and host plants in fossil sites, as well as their numerical identifiers for the PCA analysis, can be found in Appendix S2. Fossil_DT_Level_Values.csv and Appendix S3. Fossil_Plant_Level_Values.csv files respectively. Calculated network metrics at the network level for the fossil sites can be found in Appendix S4. Fossil_Network_Level_Values.csv file. List of references for modern plant-herbivore networks can be found in Appendix S8 References Modern.docx, and their calculated metrics at herbivore, plant, and whole-network levels can be found in Appendix S5. Modern_Herbivore_Level_Values.csv, Appendix S6. Modern_Plant_Level_Values.csv, Appendix S7. Modern_ Network_Level_Values.csv files. The associated code that was used to analyze the data and produce the results presented in this article is available at https://github.com/anshuman21111/fossil-herbivory-nets. All collated modern plant-herbivore network data in edgelist format can be found in on the GitHub repository.

\section{Literature Cited}

Almeida-Neto, M., and W. Ulrich. 2011. A straightforward computational approach for measuring nestedness using quantitative matrices. Environmental Modelling \& Software 26:173-178.

Almeida-Neto, M., P. Guimaraes, P. R. Guimaraes, R. D. Loyola, R. D., and W. Ulrich. 2008. A consistent metric for nestedness analysis in ecological systems: reconciling concept and measurement. Oikos 117:1227-1239.

Bascompte, J. 2010. Structure and dynamics of ecological networks. Science 329:765-766.

Bascompte, J., and P. Jordano. 2007. Plant-animal mutualistic networks: the architecture of biodiversity. Annu. Rev. Ecol. Evol. Syst., 38, pp.567-593.

Bersier, L. F., C. Banasek-Richter, and M. F. Cattin, 2002. Quantitative descriptors of food-web matrices. Ecology 83:2394-2407.

Blüthgen, N., F. Menzel, and N. Blüthgen. 2006. Measuring specialization in species interaction networks. BMC Ecology 6:9.

Blüthgen, N., J. Fründ, D. P. Vázquez, and F. Menzel. 2008. What do interaction network metrics tell us about specialization and biological traits? Ecology 89:3387-3399.

Burgos, E., H. Ceva, R. P. Perazzo, M. Devoto, D. Medan, M. Zimmermann, and A. M. Delbue. 2007. Why nestedness in mutualistic networks? Journal of Theoretical Biology 249:307-313.

Burnham, R. J. 1989. Relationships between standing vegetation and leaf litter in a paratropical forest: implications for paleobotany. Review of Palaeobotany and Palynology 58:5-32.

Burnham, R. J. 1993. Reconstructing richness in the plant fossil record. Palaios 8:376-384.

Burnham, R. J. 2008. Hide and go seek: What does presence mean in the fossil record? Annals of the Missouri Botanical Garden 95:51-71.

Burnham, R. J., S. L. Wing, and G. G. Parker. 1992. The reflection of deciduous forest communities in leaf litter: implications for authchthonous litter assemblages from the fossil record. Paleobiology 18:30-49.

Carvalho, M. R., P. Wilf, H. Barrios, D. M. Windsor, E. D. Currano, C. C. Labandeira, and C. A. Jaramillo. 2014. Insect leaf-chewing damage tracks herbivore richness in modern and ancient forests. PLoS ONE 9(5):e94950.

Chaney, R. W. 1959. Miocene floras of the Columbia Plateau. Part 1. Composition and interpretation. Publications of the Carnegie Institution of Washington 617:1-134.

Csardi, G., and T. Nepusz. 2006. The igraph software package for complex network research. InterJournal Complex Systems 1695(5):1-9.

Currano, E. D., C. C. Labandeira, and P. Wilf. 2010. Fossilized insect folivory tracks temperature for six million years. Ecological Monographs 80:547-567.

Devoto, M., S. Bailey, P. Craze, and J. Memmott. 2012. Understanding and planning ecological restoration of plant-pollinator networks. Ecology Letters 15:319-328.

Deza, M. M., and E. Deza. 2009. Encyclopedia of distances. Springer, Berlin.

DiMichele, W. A., R. W. Hook, R. Beerbower, J. Boy, R. Gastaldo, N. Hotton III, T. Phillips, S. Scheckler, W. Shear, and H. Sues. 1992. Paleozoic terrestrial ecosystems. Pp. 205-325 in A. K. Behrensmeyer, J. D. Damuth, W. A. DiMichele, R. Potts, H.-D. Sues, and S. L. Wing, eds. Terrestrial ecosystems through time. University of Chicago Press, Chicago.

DiMichele, W. A., R. W. Hook, W. J. Nelson, and D. S. Chaney. 2004. An unusual Middle Permian flora from the Blaine Formation 
(Pease River Group: Leonardian-Guadalupian Series) of King County, West Texas. Journal of Paleontology 78:765-782.

DiMichele, W. A., R. A. Gastaldo, and H. W. Pfefferkorn. 2005. Plant biodiversity partitioning in the Late Carboniferous and Early Permian and its implications for ecosystem assembly. Proceedings of the California Academy of Sciences 56:32-49.

DiMichele, W. A., C. V. Looy, and D. S. Chaney. 2011. A new genus of gigantopterid from the Middle Permian of the United States and China and its relevance to the gigantopterid concept. International Journal of Plant Sciences 172:107-119.

Dormann, C. F., B. Gruber, and J. Fründ. 2008. Introducing the bipartite package: analysing ecological networks. R News 8(2): 8-11.

Dormann, C. F., J. Fründ, N. Blüthgen, and B. Gruber. 2009. Indices, graphs and null models: analyzing bipartite ecological networks. Open Ecology Journal 2:7-24.

Dunne, J. A., R. J. Williams, N. D. Martinez, R. A. Wood, and D. A. Erwin. 2008. Compilation and network analysis of Cambrian food webs. PLoS Biology 6:0693-0708.

Dunne, J. A., C. C. Labandeira, and R. J. Williams. 2014. Highly resolved early Eocene food webs show development of modern trophic structure after the end-Cretaceous extinction. Proceedings of the Royal Society of London B 281:20133280.

Ehrlich, P. R., and P. H. Raven. 1964. Butterflies and plants: a study in coevolution. Evolution 18:586-608.

Futuyma, D. J., and A. A. Agrawal. 2009. Macroevolution and the biological diversity of plants and herbivores. Proceedings of the National Academy of Sciences USA 106:18054-18061.

Gastaldo R, W. A. DiMichele, and H. Pfefferkorn, 1996. Out of the icehouse into the greenhouse: a Late Paleozoic analog for modern global vegetational change. GSA Today 6:1-7.

Hickey, L. J. 1977. Stratigraphy and paleobotany of the Golden Valley Formation (early Tertiary) of western North Dakota. Geological Society of America Memoir 150:1-182.

Holterhoff, P. F. 2010. Sequence stratigraphy and depositional systems of the Eastern Shelf Lower Permian, central Texas: examining the tropical record of Late Paleozoic climate change: Permian Basin Section. SEPM Publication 2010-50:1-124.

Kassambara A., and F. Mundt F. 2020. Package 'factoextra': extract and visualize the results of multivariate data analyses. R package version 1.0.7. https://CRAN.R-project.org/package=factoextra, accessed 10 March 2021.

Kidwell, S. M., and D. W. J. Bosence. 1991. Taphonomy and time averaging of marine shelly faunas. In P. A. Allison, and D. E. G. Briggs, eds., Taphonomy: releasing the data locked in the fossil record. Topics in Geobiology 9:115-209. Plenum, New York.

Labandeira, C. C., and E. D. Currano. 2013. The fossil record of plant-insect dynamics. Annual Review of Earth and Planetary Sciences 41:287-311.

Labandeira, C. C., K. R. Johnson, and P. Wilf. 2002. Impact of the terminal Cretaceous event on plant-insect associations. Proceedings of the National Academy of Sciences USA 99:2061-2066.

Labandeira, C. C., P. Wilf, K. R. Johnson, and F. Marsh. 2007. Guide to insect (and other) damage types on compressed plant fossils. Department of Paleobiology, National Museum of Natural History, Smithsonian Institution, Washington, D.C. http://citeseerx.ist.psu.edu/ viewdoc/download?doi=10.1.1.212.4539\&rep=rep1\&type=pdf.

Labandeira, C. C., S. L. Tremblay, K. E. Bartowski, and L. VanAller Hernick. 2014. Middle Devonian liverwort herbivory and antiherbivore defence. New Phytologist 202:247-58.

Labandeira, C. C., E. Kustatscher, and T. Wappler. 2016. Floral assemblages and patterns of insect herbivory during the Permian to Triassic of Northeastern Italy. PLoS ONE 11(1): e0165205.

Labandeira, C. C., J. M. Anderson, and H. M. Anderson H. 2018. Expansion of arthropod herbivory in Late Triassic South Africa: the Molteno Biota, Aasvoëlberg 411 site and developmental biology of a gall. In L. H. Tanner, ed. The Late Triassic world: Earth in a time of transition. Topics in Geobiology 46:623-719. Springer, Cham, Switzerland.

Looy, C. V., and I. A. Duijnstee. 2020. Voltzian conifers of the South Ash Pasture flora (Guadalupian, Texas): Johniphyllum multinerve gen. et sp. nov., Pseudovoltzia sapflorensis sp. nov., and Wantus acaulis gen. et sp. nov. International Journal of Plant Sciences 181:363-385

López-Carretero, A., C. Díaz-Castelazo, K. Boege, and V. Rico-Gray. 2014. Evaluating the spatio-temporal factors that structure network parameters of plant-herbivore interactions. PLoS ONE 9 (10):e110430.

Maccracken, S.A., and C. C. Labandeira. 2020. The Middle Permian South Ash Pasture assemblage of north-central Texas: coniferophyte and gigantopterid herbivory and longer-term herbivory trends. International Journal of Plant Sciences 181:342-362.

MacGinitie, H. D. 1941. A middle Eocene flora from the central Sierra Nevada. Publications of the Carnegie Institution of Washington 543:1-178.

Memmott, J, N., M. Waser, and M. V. Price. 2004. Tolerance of pollination networks to species extinctions. Proceedings of the Royal Society of London B 271:2605-2611.

Michalska-Smith, M. J., and S. Allesina. 2019. Telling ecological networks apart by their structure: a computational challenge. PLoS Computational Biology 15(6):e1007076.

Mouillot, D, B. R. Krasnov, G. I. Shenbrot, and R. Poulin. 2008. Connectance and parasite diet breadth in flea-mammal webs. Oikos 31:16-20.

Muscente, A. D., A. Prabhu, H. Zhang, A. Eleish, M. B. Meyer, P. Fox, R. M. Hazen, and A. H. Knoll. 2018. Quantifying ecological impacts of mass extinctions with network analysis of fossil communities. Proceedings of the National Academy of Sciences USA 115:5217-5222.

Oksanen, J., F. G. Blanchet, R. Kindt, P. Legendre, P. R. Minchin, R. B. O'Hara, G. L. Simpson, P. Solymos, M. H. H. Stevens, H. Wagner, and M. J. Oksanen. 2013. Package 'vegan': Community ecology package, Version 2(9), 1-295. https://cran.ism.ac. jp/web/packages/vegan/vegan.pdf, accessed 10 March 2021.

Oliveira, J. B. B. S., M. L. Faria, M. A. Z. Borges, M. Fagundes, and W. S. de Araújo. 2020. Comparing the plant-herbivore network topology of different insect guilds in Neotropical savannas. Ecological Entomology 45:406-415.

Price, P. W. 2002. Resource-driven terrestrial interaction webs. Ecological Research 17:241-247.

Roopnarine, P. 2010. Graphs, networks, extinction and paleocommunity food webs. Nature Preceedings, https://doi.org/10. 1038/npre.2010.4433.1

Schachat S., C. C. Labandeira, and D. S. Chaney. 2015. Insect herbivory from early Permian Mitchell Creek flats of northcentral Texas: opportunism in a balanced component community. Palaeogeography, Palaeoclimatology, Palaeoecology 440:830-847.

Schachat, S. R., C. C. Labandeira, J. Gordon, D. S. Chaney, S. Levi, M. N. Halthore, and J. Alvarez. 2014. Plant-insect interactions from early Permian (Kungurian) Colwell Creek Pond, northcentral Texas: the early spread of herbivory in riparian environments. International Journal of Plant Sciences 175:855-890.

Schachat, S. R., C. C. Labandeira, and S. A. Maccracken. 2018. The importance of sampling standardization for comparisons of insect herbivory in deep time: a case study from the late Palaeozoic. Royal Society Open Science 5:171991.

Schachat, S. R., S. A. Maccracken, and C. C. Labandeira. 2020. Sampling fossil floras for the study of insect herbivory: how many leaves is enough? Fossil Record 23:1-18.

Shaw, J. O., E. Coco, K. Wootton, D. Daems, A. Gillreath-Brown, A. Swain, and J. A. Dunne. 2021. Disentangling ecological and 
taphonomic signals in ancient food webs. Paleobiology. doi:10.1017/pab.2020.59.

Simmons, B. I., A. R. Cirtwill, N. J. Baker, H. S. Wauchope, L. V. Dicks, D. B. Stouffer, and W. J. Sutherland. 2019. Motifs in bipartite ecological networks: uncovering indirect interactions. Oikos 128:154-170.

Stone, L., and A. Roberts. 1992. Competitive exclusion, or species aggregation? An aid in deciding. Oecologia 91:419-424.

Swain, A., M. Devereux, and W. F. Fagan. 2021. Deciphering trophic interactions in a mid-Cambrian assemblage. iScience 24(4): 102271.

Tabor, N., and C. J. Poulson. 2008. Palaeoclimate across the Late Pennsylvanian-Early Permian tropical palaeolatitudes: a reciew of climate indicators, their distribution, and relation to palaeophysiographic climate factors. Palaeogeography, Palaeoclimatology, Palaeoecology 268:293-310.
Tian, B.-L., S.-J. Wang, Y.-T. Guo, H.-Q. Li, G.-R. Chen, and H. Zhao. 1996. Flora of Palaeozoic coal balls of China. Palaeobotanist 45:448-451.

Wilf, P. 2008. Insect-damaged fossil leaves record food web response to ancient climate change and extinction. New Phytologist 178:486-502.

Wilf, P., and C. C. Labandeira. 1999. Response of plant-insect associations to Paleocene-Eocene warming. Science 284:2153-2156.

Wilf, P., C. C. Labandeira, K. R. Johnson, and B. Ellis. 2006. Decoupled plant and insect diversity after the end-Cretaceous extinction. Science 313:1112-1115.

Xu, Q.-Q., J.-H. Jin, and C. C. Labandeira. 2018. Williamson Drive: herbivory from a north-central Texas flora of latest Pennsylvanian age shows discrete component-community structure, early expansion of piercing and sucking, and plant counterdefenses. Review of Palaeobotany and Palynology 251:28-72. 